\title{
Produção Microbiana e Parâmetros Ruminais de Novilhos Alimentados com Dietas Contendo Vários Níveis de Concentrado ${ }^{1}$
}

\author{
Luís Carlos Vinhas Ítavo ${ }^{2}$, Sebastião de Campos Valadares Filho ${ }^{3}$, Fabiano Ferreira da Silva ${ }^{4}$, \\ Rilene Ferreira Diniz Valadares ${ }^{3}$, Maria Ignez Leão ${ }^{3}$, Paulo Roberto Cecon ${ }^{3}$, Camila Celeste \\ Brandão Ferreira Ítavo ${ }^{5}$, Eduardo Henrique Bevitori Kling de Moraes ${ }^{6}$, Luciana Navajas Rennó ${ }^{7}$, \\ Pedro Veiga Rodrigues Paulino 6
}

\footnotetext{
RESUMO - Objetivou-se estudar a eficiência de síntese microbiana e parâmetros ruminais em bovinos. Foram utilizados cinco bovinos da raça Nelore, não-castrados, com $165 \mathrm{~kg}$, fístulados no rúmen, abomaso e íleo. O delineamento foi em blocos casualizados com cinco períodos de coleta e quatro tratamentos. Os tratamentos consistiram de quatro níveis de concentrado na dieta (20,40, 60 e $80 \%)$. O volumoso utilizado foi feno de capim-Tifton 85 (Cynodon dactylon (L.) Pers.). As dietas foram isonitrogenadas com 15\% de proteína bruta. O indicador microbiano utilizado foi as bases purinas. As análises estatísticas do $\mathrm{pH}$ ruminal e das concentrações de $\mathrm{N}_{-} \mathrm{NH}_{3}$ foram realizadas em esquema de parcelas subdivididas, tendo na parcela os tratamentos e na subparcela o tempo de coleta. As médias para compostos nitrogenados totais presentes no abomaso e $\mathrm{N}$ microbiano foram 68,58 e $60,75 \mathrm{~g} /$ dia, respectivamente. A quantidade de carboidratos totais degradados no rúmen (CHODR) foi 1,37 kg/dia. Foi observado para a eficiência microbiana valor de 392,4 g MS microbiana/kg CHODR. A composição de bactérias e a eficiência de síntese microbiana não foram influenciadas pelo nível de concentrado das dietas.
}

Palavras-chave: níveis de concentrado, parâmetros ruminais, produção microbiana

\section{Microbial Production and Ruminal Parameters in Bullos Fed Diets Containing Different Concentrate Levels}

\begin{abstract}
It was aimed to study the efficiency of microbial synthesis and ruminal parameters in bovine. It were used five $165 \mathrm{~kg}$ growing no-castrated Nellore bulls, rumen, abomasum and ileum fistulated.A randomized blocks design with four treatments and five collection periods was used. The treatments consisted of four concentrate levels $(20,40,60$ and $80 \%)$. The roughage used was Tifton 85' (Cynodon dactylon (L.) Pers.) Bermudagrass hay. The diets were isonitrogen with $15 \%$ of crude protein. The microbial marker used was purine basis. The averages for total compound nitrogen in the abomasum and microbial nitrogen were 68.58 and $60.75 \mathrm{~g} /$ day, respectively. The amount total rumen carbohydrates degraded (CHODR) was $1.37 \mathrm{~kg} / \mathrm{day}$. It was observed for microbial efficiency 392.4 g DM microbial/kg CHODR. The bacterial composition and efficiency microbial synthesis were not affected by the concentrate level of the diets.
\end{abstract}

Key Words: concentrate levels, microbial production, ruminal parameters

\section{Introdução}

$\mathrm{O}$ pH ruminal está diretamente relacionado com os produtos finais da fermentação e também com a taxa de crescimento dos microrganismos ruminais. Tal fato é demonstrado com o uso de dietas ricas em volumosos, as quais geralmente proporcionam $\mathrm{pH}$ ruminal mais elevado, permitindo o crescimento de bactérias celulolíticas (Church, 1979). Segundo Ørskov (1986), o abaixamento do $\mathrm{pH}$ ruminal ocorre, principalmente, após a ingestão de alimentos, especialmente concentrados, devido à sua rápida taxa de fermentação. $\mathrm{O} \mathrm{pH}$ do fluido ruminal pode variar de 6,2 a 7,0 para dietas constituídas exclusivamente de volumosos.

$\mathrm{O}$ pH ruminal tem recebido atenção considerável como mecanismo que explica as reduções na ingestão e digestibilidade de volumosos, resultante da suplementação energética. Bugrwald-Balstad et al. (1995), citados por Caton \& Dhuyvetter (1997), compararam dietas à base de concentrado e volumoso, oferecidas ad libitum e reportaram consideráveis reduções e variações diurnas no $\mathrm{pH}$ ruminal associadas

\footnotetext{
${ }^{1}$ Parte da tese de Doutorado apresentada à UFV.

2 Professor da Universidade Católica Dom Bosco - UCDB, Campo Grande, MS. E.mail: itavo@ucdb.br

3 Professores da UFV, Viçosa, MG. E.mail: scvfilho@ufv.br

${ }^{4}$ Professor da UESB, Itapetinga, BA. E.mail: ffsilva@uesb.br

${ }^{5}$ Zootecnista - UFV. E.mail: ccbf_itavo@msn.com

${ }^{6}$ Estudante de Mestrado - UFV.

7 Professora da UNIOESTE - Marechal Cândido Rondon, PR.
} 
ao fornecimento de concentrado.

Mertens (1992) sugeriu que a digestão da fibra declinaria, quando o $\mathrm{pH}$ ruminal estivesse abaixo de 6,7. Ørskov (1982) e Mould et al. (1983) indicaram que o pH ruminal abaixo de 6,2 reduziria a atividade de bactérias celulolíticas e a digestão de palhas. Esses pesquisadores indicaram que a depressão no $\mathrm{pH}$ ruminal poderia ser responsável pela redução na digestibilidade da fibra associada com suplementação de grãos. Church (1979) observou que ruminantes consumindo dietas à base de volumoso mantinham o $\mathrm{pH}$ ruminal entre 6,2 e 6,8 , ao passo que aqueles que consumiram concentrado, entre 5,8 e 6,6. Mould et al. (1983) demonstraram que o efeito do $\mathrm{pH}$ na digestão da fibra é bifásico. $\mathrm{Na}$ primeira fase, pode haver acidificação de 6,8 para 6,0 , provocando redução na digestão da porção fibrosa do alimento. Após o pH do ambiente ruminal alcançar valores abaixo de 6,0; segunda fase; pode ocorrer uma parada na digestão devido à sensibilidade das bactérias fibrolíticas neste nível de acidez.

Nesse sentido, Russell et al. (1979) indicaram que a população de bactérias celulolíticas diminuiu, quando o pH variou de 5,7 a 6,2. Já as bactérias fermentadoras de carboidratos solúveis persistiram até em variações de 4,6 a 4,9. Mudanças nas populações bacterianas em resposta ao reduzido $\mathrm{pH}$, devido à sensibilidade de bactérias ruminais, poderiam ser uma das razões para a redução na ingestão e digestão do volumoso. Caton \& Dhuyvetter (1997) apresentaram em sua revisão resultados de pesquisas indicando que o $\mathrm{pH}$ ruminal não é sempre reduzido pela suplementação. Quando se analisa tal resultado, pode-se encontrar que bovinos em pastejo, suplementados com níveis crescentes de milho, não demonstraram redução no $\mathrm{pH}$ (Pordomingo et al., 1991). De fato, esses pesquisadores reportaram que o $\mathrm{pH}$ variou de 6,3 a 6,4, valores pouco acima daqueles que poderiam reduzir a ingestão e digestão de componentes da fibra, citados por Ørskov (1982).

Vanzant et al. (1990), avaliando novilhos de corte em pastejo, suplementados com níveis crescentes de sorgo $(0 ; 0,17 ; 0,32 ;$ e $0,66 \% \mathrm{PV})$, encontraram reduções lineares no $\mathrm{pH}$ ruminal. Neste estudo, o pH nunca esteve abaixo de 6,4, tornando improvável que a queda no $\mathrm{pH}$ poderia ser unicamente o responsável pelas reduções na digestibilidade da MS, a menos que os valores de 6,7 fossem aplicáveis aos dados de Vanzant et al. (1990), sugerindo que o $\mathrm{pH}$ ruminal abaixo de 6,7 poderia reduzir a digestão da fibra.

Parece que a suplementação energética pode reduzir o pH ruminal (Sanson et al., 1990). Todavia, os dados sugerem claramente que as respostas não são consistentes e que nem sempre o $\mathrm{pH}$ ruminal é grandemente afetado pela suplementação com grãos, especialmente em níveis moderados ou baixos de participação na dieta.

Quando o pH do fluido ruminal declina de 6,7 para 6,0, a taxa de utilização de carboidratos é diminuída (Strobel \& Russell, 1986). Em conclusão, os autores indicaram que mesmo pequenos declínios do $\mathrm{pH}$, típicos dos eventos ruminais de vacas leiteiras, poderiam ser prejudiciais à síntese de proteína microbiana, pois encontraram redução de $69 \%$ na síntese quando o $\mathrm{pH}$ era igual a 6,0 .

Em sua revisão, Caton \& Dhuyvetter (1997) concluíram que as reduções no $\mathrm{pH}$ ruminal associadas à suplementação com grãos poderiam explicar as reduções na digestibilidade e ingestão de forragem, porém apenas uma porção dos dados suporta tal teoria. Segundo Lana et al. (1998), as reduções no pH ruminal podem diminuir a produção de metano e amônia no rúmen, e estes efeitos apresentam potencial para melhorar a utilização de alimentos, principalmente de baixa qualidade.

A amônia é exigida por muitos microrganismos ruminais que fermentam carboidratos, alguns dos quais também requerem e/ou são estimulados por aminoácidos, peptídeos e isoácidos derivados de valina, leucina e isoleucina. O catabolismo de proteínas produz amônia no rúmen. Tal fato aponta um interesse especial, pois pode ocasionar economia de proteína, através da reciclagem, assim como problemas pelo excesso. Dessa forma, é necessário que alguma proteína seja degradada no rúmen para suprir as necessidades de peptídeos e/ou aminoácidos. A disponibilidade de carboidratos estimula o uso de amônia na síntese de aminoácidos e no crescimento microbiano (Van Soest, 1994).

Satter \& Slyter (1974) estabeleceram que $5 \mathrm{mg}$ $\mathrm{N} / 100 \mathrm{~mL}$ de fluido ruminal seriam o mínimo ideal para a ocorrência de máxima fermentação microbiana ruminal. A redução na concentração de $\mathrm{N}$ amoniacal, com níveis crescentes de concentrado, pode ser justificada pelo aumento na disponibilidade de energia ruminal, que possibilita maior utilização da amônia para o crescimento microbiano (Carvalho et al., 1997a). Entretanto, Mehrez et al. (1977) afirmaram que o máximo de atividade fermentativa ruminal é obtido quando o $\mathrm{N}$ amoniacal alcança valores entre 19 e $23 \mathrm{mg} \mathrm{N} / 100 \mathrm{~mL}$ de líquido ruminal. Já Van Soest (1994) citou como nível ótimo $10 \mathrm{mg} / 100 \mathrm{~mL}$. Todavia, este valor não deve ser considerado como um 
número fixo, devido à capacidade de síntese de proteína e captação de amônia pelas bactérias depender da taxa de fermentação dos carboidratos.

Carvalho et al. (1997b) comentaram que a redução na concentração de amônia ruminal ocorre com o aumento no nível de concentrado e pode ser justificada pelo aumento na disponibilidade de energia ruminal, que possibilita maior utilização da amônia para o crescimento microbiano. Com relação à utilização de forragem de baixa qualidade, Chase Jr. \& Hibberd (1987), fornecendo feno de Andropogon scoparius e Panicum virgatum, suplementado com fubá, encontraram um pico na produção de amônia de $5 \mathrm{mg} / 100 \mathrm{~mL}$ de fluido ruminal, três horas após o fornecimento da ração para vacas de corte.

As exigências protéicas dos ruminantes são atendidas mediante a absorção intestinal de aminoácidos provenientes, principalmente, da proteína microbiana sintetizada no rúmen e da proteína não-degradada no rúmen (Valadares Filho, 1995).

Os métodos correntes para a quantificação de compostos nitrogenados de origem microbiana baseiam-se em indicadores microbianos tais como as bases purinas (RNA), ácido 2,6 diaminopimélico (DAPA), enxofre e nitrogênio marcados $\left({ }^{35} \mathrm{Se} \mathrm{e}^{15} \mathrm{~N}\right)$. Uma comparação entre método direto, DAPA e bases purinas foi realizada por Valadares Filho et al. (1990), os quais concluíram que o método de bases purinas, descrito por Zinn e Owens (1982) e posteriormente modificado por Ushida et al. (1985), foi adequado para estimar a produção microbiana. Todavia, estes métodos envolvem a utilização de animais fistulados, o que promove interesse crescente no desenvolvimento de técnicas não invasivas (Susmel et al., 1994). A excreção de derivados de purinas está diretamente relacionada com a absorção de purinas e com o conhecimento da relação N-purinas:N-total na massa microbiana. A absorção de $\mathrm{N}$ microbiano pode ser calculada a partir da quantidade de purinas absorvida, que é estimada a partir da excreção urinária dos derivados de purinas (Chen \& Gomes, 1992).

Segundo Clark et al. (1992), 59\% da proteína que chega ao intestino delgado é de origem microbiana. Todavia, o NRC (1996) sugere que a proteína microbiana pode suprir até $100 \%$ da exigência de proteína metabolizável para bovinos de corte. Desta forma, a determinação da proteína microbiana tem sido área de interesse para o estudo da nutrição de ruminantes e a estimativa da contribuição da proteína microbiana no fluxo de proteína no intestino já está incorporada aos sistemas de avaliação de proteína em diversos países (Chen \& Gomes, 1992).

Dessa forma, o experimento foi conduzido para estimar a eficiência de síntese de proteína microbiana e a concentração de amônia e $\mathrm{pH}$ ruminal em novilhos alimentados com 20,40,60 e $80 \%$ de concentrado na dieta.

\section{Material e Métodos}

O ensaio foi conduzido no Laboratório de Animais e no Laboratório de Nutrição Animal do Departamento de Zootecnia da Universidade Federal de Viçosa, em Viçosa, MG. Foram utilizados cinco novilhos da raça Nelore não-castrados, fistulados no rúmen, abomaso e íleo (Leão \& Coelho da Silva, 1980), com peso vivo médio de $165 \mathrm{~kg}$ e alojados em baias individuais, em regime de confinamento.

Após o período de adaptação de 19 dias, foram distribuídos em delineamento em blocos casualizados com quatro tratamentos $(20,40,60$ e $80 \%$ de concentrado na dieta). $\mathrm{O}$ volumoso utilizado foi o feno de capim-Tifton 85 . Os tratamentos foram constituídos de feno de capim-Tifton 85 (Cynodon dactylon (L.) Pers.) triturado e concentrado, que constituiu 20, 40, 60 e $80 \%$ da dieta (Tabelas 1, 2 e 3). As dietas, balanceadas de acordo com o NRC (1996), foram isoprotéicas (15\% de PB) e apresentaram aproximadamente $32 \%$ da PB na forma de compostos nitrogenados não-protéicos.

Forneceu-se alimentação uma vez ao dia, ajustada de forma a manter as sobras entre 5 e $10 \%$ do oferecido. Para os tratamentos com 60 e $80 \%$ de concentrado, foram fornecidos $50 \mathrm{~g}$ de bicarbonato de sódio por dia, adicionados à ração total.

As coletas de líquido ruminal, visando a determinação do $\mathrm{pH}$ e das concentrações de $\mathrm{N}-\mathrm{NH}_{3}$, foram realizadas antes do fornecimento da dieta e após 2,4 , $6,8,10$ e 12 horas. Utilizou-se um recipiente plástico com capacidade de $250 \mathrm{~mL}$, onde o conteúdo ruminal foi coletado, por intermédio da fístula ruminal. O material coletado foi filtrado em camadas de gaze a fim de se obter $100 \mathrm{~mL}$ de líquido ruminal, procedendo-se à imediata determinação do $\mathrm{pH}$ em peagâmetro digital. Em seguida, foi adicionado a cada $100 \mathrm{~mL}$ de amostra $1 \mathrm{~mL}$ de solução de ácido clorídrico $(\mathrm{HCl})$ $1: 1$, e armazenado a $-15^{\circ} \mathrm{C}$ para posterior determinação das concentrações de $\mathrm{N}-\mathrm{NH}_{3}$.

A quantificação dos compostos nitrogenados nãoamoniacais (NNA) nas digestas de abomaso e íleo foi 
Tabela 1 - Proporção dos ingredientes nos concentrados, na base da matéria natural Table 1 - Proportion of the ingredients in concentrates, on as fed basis

\begin{tabular}{|c|c|c|c|c|}
\hline \multirow[t]{2}{*}{$\begin{array}{l}\text { Ingredientes } \\
\text { Ingredients }\end{array}$} & \multicolumn{4}{|c|}{$\begin{array}{l}\text { Nível de concentrado na dieta }(\%) \\
\text { Concentrate level in the diet }(\%)\end{array}$} \\
\hline & 20 & 40 & 60 & 80 \\
\hline Fubá de milho (\%) & 88,72 & 91,96 & 93,05 & 95,37 \\
\hline $\begin{array}{l}\text { Corn starch }(\%) \\
\text { Farelo de soja }(\%) \\
\text { Soybean meal }(\%)\end{array}$ & 4,75 & 4,38 & 4,03 & 1,75 \\
\hline $\begin{array}{l}\text { Uréia }(\%) \\
\text { Urea }(\%)\end{array}$ & 2,93 & 1,57 & 1,16 & 1,25 \\
\hline $\begin{array}{l}\text { Calcário calcítico }(\%) \\
\text { Calcite limestone }(\%)\end{array}$ & 0,05 & 0,54 & 0,88 & 1,04 \\
\hline $\begin{array}{l}\text { Fosfato bicálcico (\%) } \\
\text { Dicalcium phosphate (\%) }\end{array}$ & 2,78 & 1,12 & 0,57 & 0,33 \\
\hline $\begin{array}{l}\text { Sal comum }(\%) \\
\text { Salt }(\%)\end{array}$ & 0,70 & 0,38 & 0,28 & 0,23 \\
\hline $\begin{array}{l}\text { Sulfato de zinco }(\mathrm{g} / 100 \mathrm{~kg}) \\
\text { Zinc sulfate }(\mathrm{g} / 100 \mathrm{~kg})\end{array}$ & 67,20 & 33,60 & 22,40 & 16,80 \\
\hline $\begin{array}{l}\text { Sulfato de cobre }(\mathrm{g} / 100 \mathrm{~kg}) \\
\text { Cupper sulfate }(\mathrm{g} / 100 \mathrm{~kg})\end{array}$ & 16,00 & 8,00 & 5,32 & 4,00 \\
\hline $\begin{array}{l}\text { Sulfato de cobalto }(\mathrm{g} / 100 \mathrm{~kg}) \\
\text { Cobalt sulfate }(\mathrm{g} / 100 \mathrm{~kg})\end{array}$ & 0,21 & 0,10 & 0,07 & 0,05 \\
\hline $\begin{array}{l}\text { Iodato de potássio }(\mathrm{g} / 100 \mathrm{~kg}) \\
\text { Potassium iodate }(\mathrm{g} / 100 \mathrm{~kg})\end{array}$ & 0,42 & 0,21 & 0,14 & 0,11 \\
\hline $\begin{array}{l}\text { Selenito de sódio }(\mathrm{g} / 100 \mathrm{~kg}) \\
\text { Sodium selenite }(\mathrm{g} / 100 \mathrm{~kg})\end{array}$ & 0,21 & 0,11 & 0,07 & 0,05 \\
\hline
\end{tabular}

obtida por diferença entre o nitrogênio total e o N$\mathrm{NH}_{3}$, que foi determinado nas amostras in natura das digestas de abomaso e íleo. As concentrações de $\mathrm{N}-\mathrm{NH}_{3}$ nas amostras do líquido ruminal filtrado e nos fluidos de abomaso e íleo foram determinadas mediante destilação com hidróxido de potássio $(\mathrm{KOH}) 2 \mathrm{~N}$, conforme técnica de Fenner (1965), adaptada por Vieira (1980).
No último dia de cada período experimental, foram coletadas amostras de digesta ruminal, de cada animal, para o isolamento de bactérias, conforme metodologia descrita por Cecava et al. (1990). As análises bromatológicas das bactérias foram realizadas segundo Silva (1990).

O indicador microbiano utilizado para quantificação de microrganismos, nas digestas ruminal

Tabela 2 - Teores médios de matéria seca (MS), matéria orgânica (MO), proteína bruta (PB), extrato etéreo (EE), fibra em detergente neutro (FDN), carboidratos não-fibrosos (CNF), cálcio (Ca) e fósforo (P) dos concentrados e do feno

Table 2 - Average contents of dry matter (DM), organic matter (OM), crude protein (CP), ether extract (EE), neutral detergent fiber $(N D F)$, non fiber carbohydrates (NFC), calcium (Ca) and phosphorus (P) of concentrates and hay

\begin{tabular}{|c|c|c|c|c|c|}
\hline \multirow[t]{2}{*}{ Itens } & \multirow[t]{2}{*}{$\begin{array}{c}\text { Feno } \\
\text { Hay }\end{array}$} & \multicolumn{4}{|c|}{$\begin{array}{l}\text { Nível de concentrado na dieta }(\%) \\
\text { Concentrate level in the diet }(\%)\end{array}$} \\
\hline & & 20 & 40 & 60 & 80 \\
\hline $\operatorname{MS}(D M), \%$ & 88,55 & 87,30 & 87,29 & 87,33 & 88,55 \\
\hline $\operatorname{MO}(O M)^{1}$ & 94,18 & 95,77 & 96,37 & 97,02 & 96,55 \\
\hline $\mathrm{PB}(C P)^{1}$ & 14,09 & 21,98 & 16,62 & 15,78 & 14,63 \\
\hline $\mathrm{EE}^{1}$ & 1,93 & 2,78 & 4,30 & 2,66 & 1,89 \\
\hline FDN $(N D F)^{1,2}$ & 74,47 & 14,01 & 9,86 & 13,53 & 13,81 \\
\hline $\mathrm{CNF}(N F C)^{1}$ & 3,69 & 57,00 & 65,59 & 65,05 & 66,22 \\
\hline $\mathrm{Ca}^{1}$ & 0,36 & 0,96 & 0,70 & 0,71 & 0,84 \\
\hline $\mathrm{P}^{1}$ & 0,20 & 0,95 & 0,48 & 0,40 & 0,50 \\
\hline
\end{tabular}

$1 \%$ na matéria seca (\% in dry matter).

2 FDN corrigida para cinzas e proteína (NDF corrected for ash and protein).

\section{R. Bras. Zootec., v.31, n.3, p.1553-1561, 2002 (suplemento)}


Tabela 3 - Teores médios de matéria seca (MS), matéria orgânica (MO), proteína bruta (PB), extrato etéreo (EE), fibra em detergente neutro (FDN), carboidratos não fibrosos (CNF), nutrientes digestíveis totais (NDT), cálcio (Ca) e fósforo $(P)$ das dietas experimentais

Table 3 - Average contents of dry matter (DM), organic matter (OM), crude protein (CP), ether extract (EE), neutral detergent fiber (NDF), non fiber carbohydrates (NFC), total digestible nutrients (TDN), calcium (Ca) and phosphorus (P) of experimental diets

\begin{tabular}{|c|c|c|c|c|}
\hline \multirow[t]{2}{*}{ Itens } & \multicolumn{4}{|c|}{$\begin{array}{l}\text { Nível de concentrado na dieta }(\%) \\
\text { Concentrate level in the diet }(\%)\end{array}$} \\
\hline & 20 & 40 & 60 & 80 \\
\hline $\mathrm{MS}(D M), \%$ & 88,21 & 88,05 & 87,79 & 87,58 \\
\hline $\mathrm{MO}(O M)^{1}$ & 94,50 & 95,06 & 95,88 & 96,08 \\
\hline $\mathrm{PB}(C P)^{1}$ & 15,67 & 15,10 & 15,11 & 14,52 \\
\hline $\mathrm{EE}^{1}$ & 2,30 & 3,03 & 2,46 & 1,95 \\
\hline FDN $(N D F)^{1,2}$ & 62,37 & 48,62 & 37,90 & 25,94 \\
\hline $\mathrm{CNF}(N F C)^{1}$ & 14,16 & 28,31 & 40,41 & 53,67 \\
\hline $\operatorname{NDT}(T D N)^{1}$ & 73,80 & 77,73 & 79,61 & 81,94 \\
\hline $\mathrm{Ca}^{1}$ & 0,48 & 0,50 & 0,57 & 0,74 \\
\hline $\mathrm{P}^{1}$ & 0,35 & 0,31 & 0,32 & 0,44 \\
\hline
\end{tabular}

$1 \%$ na matéria seca (\% in dry matter).

2 FDN corrigida para cinzas e proteína (NDF corrected for ash and protein).

e abomasal, foi bases purinas, cuja determinação seguiu a técnica descrita por Ushida et al. (1985).

As variáveis foram avaliadas por meio de análises de variância e regressão, utilizando-se o Sistema de Análises Estatísticas e Genéticas - SAEG (UFV/ CPD, 1997). Os modelos estatísticos foram escolhidos de acordo com a significância dos coeficientes de regressão, utilizando-se o teste $\mathrm{F}$ em nível de 5\%, coeficiente de determinação $\left(\mathrm{r}^{2}\right)$ e o fenômeno biológico estudado. As análises estatísticas do $\mathrm{pH}$ ruminal e das concentrações de $\mathrm{N}-\mathrm{NH}_{3}$ foram realizadas em esquema de parcelas subdivididas, tendo na parcela os tratamentos e na subparcela o tempo de coleta.

\section{Resultados e Discussão}

Os resultados de composição bromatológica das bactérias isoladas dos bovinos alimentados com rações contendo níveis crescentes de concentrado e a relação entre nitrogênio proveniente do RNA microbiano e nitrogênio total (N-RNA:NT) estão apresentados na Tabela 4. Observa-se que não houve efeito $(\mathrm{P}>0,05)$ dos níveis de concentrado sobre as variáveis estudadas. Os valores de MS variaram de 71,2 a $74,8 \%$ e foram menores aos valores apresentados por Oliveira et al. (1999), que apresentaram média de $94,92 \%$. Tais valores foram inferiores aos encontrados na literatura (Valadares Filho, 1995; Villela et al., 1995; Rabello, 1995; Dutra, 1996; Carvalho et al., 1997a). Todavia, Valadares Filho (1995), em sua revisão, observou grandes variações nos teores de matéria orgânica de bactérias isoladas, com valores entre 77,5 e $84,6 \%$.

Para a relação N-RNA:NT, observou-se valor médio de 14,78, semelhante ao valor médio de 15,3 encontrado por Carvalho et al. (1997a) e maior do que 8,3 registrado por Tibo et al. (2000) e 8,52 relatado por Oliveira et al. (1999), que utilizaram cama de frango e microbiota ruminal liofilizada. Por sua vez, Dias et al. (2000) encontraram efeito linear decrescente, em função do aumento do nível de concentrado da dieta, com valores de 12,94 e 4,42 para os níveis de 25 e $75 \%$ de concentrado, respectivamente.

As médias e equações de regressão ajustadas para os compostos nitrogenados totais (NT) no abomaso, $\mathrm{N}$ microbiano (NMic) no abomaso, carboidratos totais degradados no rúmen, eficiência microbiana expressa em relação aos carboidratos totais estão apresentadas na Tabela 5. O nível de concentrado da dieta não influenciou as variáveis estudadas. As médias para NT no abomaso e N microbiano foram 68,58 e $60,75 \mathrm{~g} /$ dia, respectivamente. Tais valores foram maiores do que as médias 57,84 e 43,62 g/dia, para NT no abomaso e N microbiano, respectivamente, apresentadas por Carvalho et al. (1997a), que avaliando níveis de concentrado na dieta de bovinos, não observaram seu efeito para ambas variáveis. Todavia, os valores de eficiência expressa em gMS/kg CHODR foram semelhantes aos valores de Carvalho et al. (1997a). 
Tabela 4 - Composição bromatológica de bactérias isoladas de bovinos alimentados com níveis crescentes de concentrado na dieta e relação nitrogênio proveniente do RNA microbiano e $\mathrm{N}$ total

Table 4 - Chemical composition of isolated bacteria in bovines fed diet with increasing levels of concentrate and with microbial nitrogen RNA: total $N$ ratio

\begin{tabular}{|c|c|c|c|c|c|}
\hline \multirow[t]{2}{*}{$\begin{array}{l}\text { Variáveis } \\
\text { Variables }\end{array}$} & \multicolumn{4}{|c|}{$\begin{array}{l}\text { Nível de concentrado }(\%) \\
\text { Concentrate level (\%) }\end{array}$} & \multirow[t]{2}{*}{ CV $(\%)$} \\
\hline & 20 & 40 & 60 & 80 & \\
\hline $\operatorname{MS}(D M)^{1}(\%)$ & 73,45 & 74,77 & 73,35 & 71,22 & 3,06 \\
\hline $\mathrm{CZ}^{2}($ Ash $)(\%)$ & 19,92 & 21,15 & 21,09 & 20,51 & 9,55 \\
\hline $\mathrm{PB}^{3}(\%$ da MS $)$ & 73,22 & 75,47 & 73,37 & 71,22 & 3,03 \\
\hline $\begin{array}{l}C P(\% \text { in } D M) \\
\mathrm{EE}^{4}(\% \text { da } \mathrm{MS}) \\
E E(\% \text { in } D M)\end{array}$ & 4,97 & 3,52 & 5,34 & 5,25 & 28,73 \\
\hline NRNA:NT ${ }^{5}$ & 15,93 & 15,45 & 14,21 & 13,54 & 12,66 \\
\hline
\end{tabular}

MS = matéria seca; $C Z$ = cinzas; $P B=$ proteína bruta $(N \times 6,25)$; EE = extrato etéreo; NRNA:NT = relação N-RNA microbiano e N total.

* Significância das equações de regressão $(P<0,10)$.

$1 \mathrm{Y}=73,20 ;{ }^{2} \mathrm{Y}=20,67 ; 3^{3} \mathrm{Y}=73,32 ; 4 \mathrm{Y}=4,77 ; 5 \mathrm{Y}=14,78$

$D M=$ dry matter; $A$ sh; $C P=$ crude protein (Nx6.25); $E E=$ ether extract; NRNA:NT = microbial N-RNA:total $N$.

* Significance of regression equations $(P<.10)$.

Ao contrário, Berchielli et al. (1995), estudando o efeito do nível de concentrado da dieta de bovinos sobre a quantidade de $\mathrm{N}$ total presente no abomaso, encontra$\operatorname{ram} 78,82$ e $89,53 \mathrm{~g} /$ dia de $\mathrm{N}$ total para as dietas com 40 e $60 \%$ de concentrado, respectivamente.

Os valores de $\mathrm{N}$ total no abomaso foram menores do que os 88,72 e $108,40 \mathrm{~g} /$ dia para os níveis de concentrado 30 e $60 \%$, respectivamente, obtidos por Bürger et al. (2000). Estes autores encontraram valores linearmente crescentes em função do nível de concentrado na dieta. Rennó et al. (2000), estu- dando a produção de proteína microbiana através dos derivados de purinas na urina, observaram efeito dos níveis de concentrado sobre o nitrogênio microbiano, em que os valores médios foram $80,8 \mathrm{~g} /$ dia para animais mestiços (europeu x nelore) e 63,76 g/dia para animais zebuínos. Esses valores de nitrogênio microbiano no abomaso, para animais zebuínos, são similares aos valores apresentados na Tabela 5. Dias et al. (2000), avaliando a eficiência de síntese microbiana em novilhos com peso médio de $268 \mathrm{~kg}$, encontraram $60,77 \mathrm{~g} /$ dia de $\mathrm{N}$ microbiano no abomaso,

Tabela 5 - Compostos nitrogenados totais (NT) e N microbiano (NMic) presentes no abomaso, carboidratos totais degradados no rúmen (CHODR), eficiência microbiana, expressa em gNMic/kgCHODR, gMSmic/kg CHODR, em função do nível de concentrado na dieta

Table 5 - Total nitrogen compounds (TN) and microbial nitrogen (MicN) present in the abomasum, total carbohydrates degraded in the rumen (CHODR), microbial efficiency, express in gMicN/kgCHODR, gmicDM/kg CHODR, on the concentrate level in the diet

\begin{tabular}{|c|c|c|c|c|c|}
\hline \multirow[t]{2}{*}{$\begin{array}{l}\text { Variáveis } \\
\text { Variables }\end{array}$} & \multicolumn{4}{|c|}{$\begin{array}{c}\text { Nível de concentrado (\%) } \\
\text { Concentrate level (\%) }\end{array}$} & \multirow[t]{2}{*}{$\mathrm{CV}(\%)$} \\
\hline & 20 & 40 & 60 & 80 & \\
\hline $\begin{array}{l}\text { NT no abomaso }{ }^{1}(\mathrm{~g} / \mathrm{dia}) \\
\text { TN in the abomasum }(\mathrm{g} / \text { dav })\end{array}$ & 68,08 & 76,31 & 75,46 & 59,91 & 26,97 \\
\hline $\begin{array}{l}\text { NMic no abomaso }{ }^{2} \text { (g/dia) } \\
\text { MicN in the abomasum (g/day) }\end{array}$ & 56,68 & 71,57 & 58,85 & 57,40 & 39,48 \\
\hline $\mathrm{CHODR}^{3}(\mathrm{~kg} / \mathrm{d})$ & 1,27 & 1,39 & 1,37 & 1,45 & 23,33 \\
\hline $\begin{array}{l}\mathrm{gNMic} / \mathrm{kgCHODR}{ }^{4} \\
\text { gMicN/kgCHODR }\end{array}$ & 45,90 & 52,06 & 44,51 & 41,97 & 43,82 \\
\hline $\begin{array}{l}\mathrm{gMSmic} / \mathrm{kgCHODR}^{5} \\
\mathrm{gMicD} / \mathrm{kgCHODR}\end{array}$ & 392,31 & 444,93 & 380,42 & 358,69 & 43,82 \\
\hline
\end{tabular}

* Significância das equações de regressão $(P<0,10)$.

${ }^{1} \mathrm{Y}=68,58 ;{ }^{2} \mathrm{Y}=60,75 ; 3^{3} \mathrm{Y}=1,37 ;{ }^{4} \mathrm{Y}=45,91 ;{ }^{5} \mathrm{Y}=392,40$

* Significance of regression equations $(P<.10)$.

\section{R. Bras. Zootec., v.31, n.3, p.1553-1561, 2002 (suplemento)}


para o nível de $50 \%$ de concentrado. Também Ladeira et al. (1999) apresentaram resultados semelhantes de $60,37 \mathrm{~g} /$ dia de $\mathrm{N}$ microbiano no abomaso.

Foi observado valor médio de $392,4 \mathrm{gMSmic} / \mathrm{kg}$ CHODR. Este valor é maior do que os 320,35 gMSmic/ kg CHODR encontrados por Ladeira et al. (1999), trabalhando com novilhos Nelore de 244,6 kg. Dias et al. (2000), também não observaram efeito do nível de concentrado sobre a eficiência microbiana. Todavia, Tibo et al. (2000) encontraram efeito linear do nível de concentrado sobre a eficiência microbiana expressa em relação aos carboidratos degradáveis no rúmen, apresentando para os níveis de 25, 62,5 e 75\% de concentrado, valores de 371,60; 474,51; e 641,32 $\mathrm{g} \mathrm{MSmic/kg} \mathrm{CHODR,} \mathrm{respectivamente.}$

As médias e equações de regressão ajustadas para $\mathrm{N}$-amoniacal e para $\mathrm{pH}$ do líquido ruminal de novilhos Nelore, em função do nível de concentrado na dieta e do tempo, estão apresentadas nas Tabelas 6 e 7. Observou-se que os valores de $\mathrm{N}$-amoniacal para todos os tratamentos foram maiores do que os 5 $\mathrm{mg}$ de $\mathrm{N} / 100 \mathrm{~mL}$, nível mínimo necessário para manter as funções normais do rúmen, citado por Satter \& Slyter (1974).

Estimaram-se concentrações máximas de $\mathrm{N}$ amoniacal em 22,93 $\mathrm{mg}$ de $\mathrm{N} / 100 \mathrm{~mL}$ de líquido ruminal com $14,14 \%$ de concentrado e 1,89 horas após o fornecimento da dieta. Os valores encontrados para as máximas concentrações de $\mathrm{N}$-amoniacal das dietas, em função do tempo de coleta (Tabela 6), estão de acordo com Mehrez et al. (1977), os quais sugeriram que a máxima atividade fermentativa ocorreria quando as concentrações de $\mathrm{N}$ amoniacal estiverem entre 19 e $23 \mathrm{mg}$ de $\mathrm{N} / 100 \mathrm{~mL}$ de líquido ruminal. Van Soest (1994) relatou que o suprimento de $\mathrm{N}$ no rúmen promove o crescimento microbiano até o limite das exigências dos microrganismos. Todavia, essa exigência estaria relacionada aos carboidratos fermentescíveis disponíveis, à produção de ATP e à eficiência de conversão em células microbianas.

Com relação ao pH do líquido ruminal dos novilhos, pode-se observar que há lenta queda no $\mathrm{pH}$ com o aumento do tempo de coleta (Tabela 7). O valor

Tabela 6 - Médias e equação de regressão ajustada para N-amoniacal (mg de N/100 mL de líquido ruminal) de novilhos Nelore, em função dos níveis $(n)$ de concentrado na dieta e do tempo $(t)$ de coleta e seu coeficiente de determinação

Table 6 - Means and fitted regression equation for ammoniacal $N$ ( $\mathrm{mg} \mathrm{N} / 100 \mathrm{~mL}$ of ruminal fluid) of Nellore bulls, on the level of concentrate $(n)$ in the diet and of collection time $(t)$ and its coefficient of determination

\begin{tabular}{ccccccc}
\hline \begin{tabular}{c} 
Nível de concentrado (\%) $\begin{array}{c}\text { Tempo de coleta (horas) } \\
\text { Concentrate level (\%) }\end{array}$ \\
\cline { 2 - 7 }
\end{tabular} & 0 & 2 & 4 & 6 & 8 & 10 \\
\hline 20 & 15,13 & 32,15 & 23,47 & 17,20 & 15,40 & 13,40 \\
40 & 15,00 & 36,40 & 29,24 & 19,00 & 14,55 & 14,10 \\
60 & 16,50 & 27,05 & 19,16 & 12,06 & 11,80 & 10,95 \\
80 & 14,33 & 19,87 & 25,26 & 12,88 & 10,96 & 14,58 \\
\hline
\end{tabular}

$\mathrm{Y}_{\mathrm{NNH} 3}=22,3438+0,0270523 n-0,000956568 n^{2}+0,419002 t-0,110758 t^{2}\left(R^{2}=0,87\right)$.

Tabela 7 - Médias e equação de regressão ajustada para pH no líquido ruminal de novilhos Nelore, em função dos níveis $(n)$ de concentrado na dieta e do tempo $(t)$ de coleta e seu coeficiente de determinação

Table 7 - Means and fitted regression equation for $\mathrm{pH}$ in the ruminal fluid of Nellore bulls, on the concentrate level ( $n$ ) in the diet and of collection time $(t)$ and its coefficient of determination

\begin{tabular}{|c|c|c|c|c|c|c|c|}
\hline \multirow[t]{2}{*}{$\begin{array}{c}\text { Nível de concentrado (\%) } \\
\text { Concentrate level (\%) }\end{array}$} & \multicolumn{7}{|c|}{$\begin{array}{c}\text { Tempo de coleta (horas) } \\
\text { Collection time (hours) }\end{array}$} \\
\hline & 0 & 2 & 4 & 6 & 8 & 10 & 12 \\
\hline 20 & 6,52 & 6,66 & 6,59 & 6,29 & 6,41 & 6,39 & 6,44 \\
\hline 40 & 6,64 & 6,78 & 6,60 & 6,36 & 6,29 & 6,43 & 6,43 \\
\hline 60 & 6,35 & 6,48 & 6,15 & 5,90 & 6,17 & 6,24 & 6,34 \\
\hline 80 & 7,03 & 7,14 & 7,18 & 6,79 & 6,67 & 6,50 & 6,61 \\
\hline
\end{tabular}

$\mathrm{Y}_{\mathrm{pH}}=7,2405-0,0306382 n+0,000349208 n^{2}-0,0648376 t+0,00302489 t^{2}\left(\mathrm{R}^{2}=0,98\right)$.

R. Bras. Zootec., v.31, n.3, p.1553-1561, 2002 (suplemento) 
mínimo de $\mathrm{pH}$ foi 6,22 ; estimado com $43,86 \%$ de concentrado e 10,72 horas após a alimentação. Observa-se que os menores valores para o $\mathrm{pH}$ estiveram sempre acima de 6,0; valor mínimo citado por Mould et al. (1983).

As dietas contendo 60 e $80 \%$ de concentrado, nas quais foi adicionado bicarbonato de sódio a fim de manter o pH acima de 6,2; valor citado por Ærskov (1982) e Mould et al. (1983) que poderia reduzir a atividade de bactérias celulolíticas. Observa-se na Tabela 7 que os valores de $\mathrm{pH}$ do líquido ruminal dos novilhos que receberam a dieta com $80 \%$ de concentrado apresentaram-se acima de 6,5; indicando a eficiência do efeito de tamponamento ruminal do bicarbonato de sódio.

\section{Conclusões}

A composição de bactérias e a eficiência de síntese microbiana não foram influenciadas pelo nível de concentrado das dietas, embora tenha se registrado efeito do nível de concentrado para $\mathrm{N}$ amoniacal e $\mathrm{pH}$ ruminal.

\section{Literatura Citada}

BERCHIELLI, T.T.; RODRIGUEZ, N.M.; GONÇALVES, L.C. et al. Fluxo de nitrogênio duodenal e degradabilidade ruminal do nitrogênio da dieta estimado por meio de três marcadores microbianos. Revista da Sociedade Brasileira de Zootecnia, v.24, n.5, p.810-819, 1995.

BÜRGER, P.J.; PEREIRA, J.C.; VALADARES FILHO, S.C. et al. Fermentação ruminal e eficiência microbiana em bezerros holandeses alimentados com dietas contendo diferentes níveis de concentrado. Revista Brasileira de Zootecnia, v.29, n.1, p.215-224, 2000.

CARDOSO, R.C.; VALADARES FILHO, S.C.; COELHO DA SILVA, J.F. et al. Síntese microbiana, $\mathrm{pH}$ e concentração de amônia ruminal e balanço de compostos nitrogenados, em novilhos F1 limousin $x$ nelore. Revista Brasileira de Zootecnia, v.29, n.6, p.1844-1852, 2000.

CARVALHO, A.U., VALADARES FILHO, S.C., COELHO DA SILVA, J.F. et al. Níveis de concentrado em dietas de zebuínos. 3. Eficiência microbiana e população de protozoários ruminais. Revista Brasileira de Zootecnia, v.26, n.5, p.1007-1015, 1997a.

CARVALHO, A.U.; VALADARES FILHO, S.C.; COELHO DA SILVA, J.F. et al. Níveis de concentrado em dietas de zebuínos. 4. Concentrações ruminais de amônia e pH, taxa de passagem da digesta ruminal e degradação in situ dos alimentos. Revista Brasileira de Zootecnia, v.26, n.5, p.10161024, 1997b.

CATON, J.S.; DHUYVETTER, D.V. Influence of energy supplementation on grazing ruminants: requirements and responses. Journal of Animal Science, v.75, p.533-542, 1997.
CECAVA, M.J.; MERCHEN, N.R.; GAY, L.C. et al. Composition of ruminal bacteria harvest from steers as influenced by dietary energy level, feeding frequency, and isolation techniques. Journal of Dairy Science, v.73, n.9, p.2480-2488, 1990.

CHASE JR., C.; HIBBERD, C.A. Utilization of low-quality native grass hay by beef cows fed increasing quantities of corn grain. Journal of Animal Science, v.65, n.2, p.557566, 1987.

CHEN, X.B.; GOMES, M.J. Estimation of microbial protein supply to sheep and cattle based on urinary excretion of purine derivates - an overview of technical details. (Occasional publication) INTERNATIONAL FEED RESEARCH UNIT. Bucksburnd, Aberdeen: Rowett Research Institute, 1992. 21p.

CHURCH, D.C. Digestive physiology and nutrition of ruminants. Vol. 1 - Digestive Physiology. 3.ed. Oxford: Oxford Press Inc., 1979. 350p.

CLARK, J.H.; KLUSMEYER, T.H.; CAMERON, M.R. Microbial protein synthesis and flows of nitrogen fractions to the duodenum of dairy cows. Journal of Dairy Science, v.75, p.2304-2323, 1992.

DIAS, H.L.C.; VALADARES FILHO, S.C.; COELHO DA SILVA, J.F. et al. Eficiência de síntese microbiana, $\mathrm{pH}$ e concentrações ruminais de amônia em novilhos F1 limousin $\mathrm{x}$ nelore alimentados com dietas contendo cinco níveis de concentrado. Revista Brasileira de Zootecnia, v.29, n.2, p.555-563, 2000.

KREHBIEL, C.R.; FERRELL, C.L.; FREETLY, H.C. Effects of frequency of supplementation on dry matter intake and net portal and hepatic flux of nutrients in mature ewes that consume low-quality forage. Journal of Animal Science, v.76, p.2464-2473, 1998.

LADEIRA, M.M.; VALADARES FILHO, S.C.; LEÃO, M.I. et al. Eficiência microbiana, concentração de amônia e pH ruminal e perdas nitrogenadas endógenas em novilhos Nelore. Revista Brasileira de Zootecnia, v.28, n.2, p.404-411, 1999.

LANA, R.P.; RUSSELL, J.B.; Van AMBURGH, M.E. The role of $\mathrm{pH}$ in regulating ruminal methane and ammonia production. Journal of Animal Science, v.76, p.2190-2196, 1998.

LEÃO, M.I., COELHO DA SILVA, J.F. Técnicas de fistulação de abomaso em bezerros. In: CONGRESSO BRASILEIRO DE ZOOTECNIA, 1. REUNIÃO ANUAL DA SOCIEDADE BRASILEIRA DE ZOOTECNIA, 17., 1980, Fortaleza. Anais... Fortaleza: Sociedade Brasileira de Zootecnia, 1980. p.37.

MEHREZ, A.Z.; ÆRSKOV, E.R.; McDONALD, I. Rates of rumen fermentation in relation to ammonia concentration. British Journal Nutrition, v.38, n.3, p.437-443, 1977.

MERTENS, D.R. Analysis of fiber in feeds and its use in feed evaluation and ration formulation. In: SIMPÓSIO INTERNACIONAL DE RUMINANTES, 1992, Lavras, MG. Anais...Lavras: Universidade Federal de Lavras, 1992. p.1-32.

MOULD, F.L.; $\varnothing$ RSKOV, E.R.; MANN, S.O. Associative effects of mixed feeds. 2 . The effect of dietary additions of bicarbonate salts on the voluntary intake and digestibility of diets containing various proportions of hay and barley. Animal Feed Science and Technology, v. 10, p. $15-25,1983$.

NATIONAL RESEARCH COUNCIL - NRC. Nutrient requirements of beef cattle. 7.ed. Washington, D.C.: National Academy Press, 1996. 242p. 
OLIVEIRA, R.L.; PEREIRA, J.C.; SILVA, P.R.C. et al. Características ruminais e eficiência de síntese microbiana em novilhos alimentados com cama de frango e suplemento à base de microbiota ruminal liofilizada. Revista Brasileira de Zootecnia, v.28, n.5, p.1118-1124, 1999.

$\varnothing \mathrm{RSKOV}$, E.R. Protein nutrition in ruminants. London: Academic Press. 1982. 160p.

$\varnothing$ RSKOV, E.R. Starch digestion and utilization in ruminants. Journal of Animal Science, v.63, n.5, p.1624-1633, 1986.

PORDOMINGO, A.J.; WALLACE, J.D.; FREEMAN, A.S. et al. Supplemental corn grain for steers grazing native rangeland during summer. Journal of Animal Science, v.69, p.16781684, 1991.

RENNÓ, L.N.; VALADARES, R.F.D.; LEÃO, M.I. et al. Estimativa da produção de proteína microbiana pelos derivados de purinas na urina em novilhos. Revista Brasileira de Zootecnia, v.29, n.4, p.1223-1234, 2000.

RUSSELL, J.B.; SHARP, W.M.; BALDWIN, R.L. The effect of $\mathrm{pH}$ on maximum bacterial growth rate and its possible role as a determinant of bacterial competition in the rumen. Journal of Animal Science, v.48, p.251-258, 1979

SANSON, D.W.; CLANTON, D.C.; RUSH, I.G. Intake and digestion of low-quality meadow hay by steers and performance of cows on native range when fed protein supplements containing various levels of corn. Journal of Animal Science, v.68, p.595-603, 1990.

SATTER, L.D.; SLYTER, L.L. Effect of ammonia concentration on rumen microbial protein production in vitro. British Journal Nutrition, v.32, n.2, p.199-208, 1974.

SILVA, D.J. Análise de alimentos (Métodos químicos e biológicos). Viçosa, MG: Universidade Federal de Viçosa, 1990. $165 \mathrm{p}$.

STROBEL, H.L.; RUSSELL, J.B. Effect of $\mathrm{pH}$ and energy spilling on bacterial protein synthesis by carbohydratelimited cultures of mixed rumen bacteria. Journal of Dairy Science, v.69, n.11, p.2941-2947, 1986.

TIBO, G.C.; VALADARES FILHO, S.C.; COELHO DA SILVA, J.F. et al. Níveis de concentrado em dietas de novilhos mestiços F1 Simental x Nelore. 2. Balanço nitrogenado, eficiência microbiana e parâmetros ruminais. Revista Brasileira de Zootecnia, v.29, n.3, p.921-929, 2000.
USHIDA, K.; LASSALAS, B.; JOUANY, J.P. Determination of assay parameters for RNA analysis in bacterial and duodenal samples by spectrophotometry. Influence of sample treatment and preservation. Reproducion Nutrition Development., v.25, n.6, p.1037-1046, 1985.

UNIVERSIDADE FEDERAL DE VIÇOSA. Central de Processamento de dados (UFV/CPD). Manual de utilização do Programa SAEG (Sistema para Análises Estatísticas e Genéticas). Viçosa, MG: Universidade Federal de Viçosa, 1997. 59p.

VALADARES FILHO, S.C. Eficiência de síntese de proteína microbiana, degradação ruminal e digestibilidade intestinal da proteína bruta em bovinos. In: SIMPÓSIO INTERNACIONAL SOBRE EXIGÊNCIAS NUTRICIONAIS DE RUMINANTES, 1995, Viçosa, MG. Anais...Viçosa: Universidade Federal de Viçosa, 1995. p.355-388.

VALADARES FILHO, S.C.; COELHO DA SILVA, J.F.; LEÃO, M.I. et al. Eficiência de síntese microbiana em novilhos holandeses, nelores e búfalos mestiços, obtida por diferentes métodos. Revista da Sociedade Brasileira de Zootecnia, v.19, n.5, p.424-430, 1990.

Van SOEST, P.J. Nutritional ecology of the ruminant. Ithaca: Comstock Publ. Assoc., 1994. 476p.

VANZANT, E.S.; COCHRAN R.C.; JACQUES, K.A. et al. Influence of level of supplementation and type of grain in supplements on intake and utilization of harvested, earlygrowing-season bluestem-range forage by beef steers. Journal of Animal Science, v.68, p.1457-1464, 1990.

VIEIRA, P.F. Efeito do formaldeído na proteção de proteínas e lipídios em rações para ruminantes. Viçosa, MG: \{Universidade Federal de Viçosa, 1980. 98p. Tese (Doutorado em Zootecnia) - Universidade Federal de Viçosa, 1980.

Recebido em: 10/08/01

Aceito em: 13/02/02 